\title{
Effectiveness of the talent cultivation training program for industry transformation in Taiwan during the COVID-19 pandemic
}

\section{Fang-Yi Lin ${ }^{1}$}

Received: 30 October 2020 / Accepted: 15 July 2021 / Published online: 20 July 2021

(C) The Author(s), under exclusive licence to Springer-Verlag GmbH Germany, part of Springer Nature 2021

\begin{abstract}
In response to the impact of the COVID-19 pandemic on the Taiwanese tourism and hospitality industry, the Taiwanese government launched an industry revival and revitalization project. Subsidies were given for cultivating talent and industry transformation. The industry implemented talent cultivation courses to improve the skills and knowledge of workers and facilitate financial subsidization. This study reviewed the talent cultivation subsidy and training results for employees participating in training programs within Taiwan's lodging industry. The results showed that the government promoted large-scale industry transformation and talent cultivation, and industry employees who received the training responded to it positively.
\end{abstract}

Keywords COVID-19 - Taiwan · Lodging industry · Talent cultivation training for industry transformation · Training effectiveness

\section{Introduction}

According to regulations for construction-related equipment and their governance, Taiwan's lodging businesses are classified into two categories, namely tourist hotel and hotel enterprises. Tourist hotel enterprises are further categorized into international and regular tourist hotels. Regulation of the construction of tourist hotels by the central government of Taiwan is strict and extensive (R.O.C. Laws \& Regulations Database, Ministry of Justice 2016a,2016b). As of 2020, Taiwan had 127 tourist hotel enterprises and 3374 hotel enterprises. In 2019, the total operating income of these enterprises was approximately US\$5.2 billion, with the 127 tourist hotel enterprises accounting for $40 \%$ of this income (Executive Information System, Tourism Bureau, Ministry of Transportation and Communications [MOTC] 2020a).

Fang-Yi Lin

flin@mail.shu.edu.tw

1 Department of Tourism, School of Management, Shih Hsin University, No.111, Mu-Cha Rd., Sec.1, Taipei 11604, Taiwan 
The annual operation income of tourist hotel enterprises in Taiwan in 2019 was approximately US\$1.07 billion, whereas the number of rooms available throughout 2019 was approximately 350,000. In 2019, the average occupancy rate was $67 \%$ and average room price was US\$130 (Executive Information System, Tourism Bureau, MOTC 2020a). Taiwan had its first COVID-19 case on January 21, 2020 (Ministry of Health and Welfare 2020), and the occupancy rate of tourist hotels has since declined. Compared with the same period in 2019, the occupancy rate was approximately 5\%, 46\%, 74\%, and 78\% lower in January, February, March, and April 2020, respectively. The mean rate of decline in hotel room occupancy from January to June 2020 was 54\%. From January to June 2020 , the overall room income was US\$200 million (56\% lower than the same period in 2019) and the income from catering was approximately US\$300 million (34\% lower than the same period in 2019; Executive Information System, Tourism Bureau, MOTC 2020a). The annual operation income of hotel enterprises in Taiwan was approximately US\$3.1 billion in 2019. The number of rooms available throughout the year was approximately 57,000,000. The average occupancy rate was $52 \%$, and the average room price was US\$76. These figures were also affected in 2020. The negative impact of COVID-19 was strongest in April 2020, when the occupancy rate of Taiwanese hotel enterprises was only $20.27 \%(43 \%$ lower than the same month in 2019; Executive Information System, Tourism Bureau, MOTC 2020a).

Due to the COVID-19 pandemic, various countries are practicing social distancing, warning against gatherings, and exerting border control. Consequently, the catering, accommodation, entertainment, transportation, and tourism industries worldwide have been severely affected by the COVID-19 pandemic. In response to the impact of COVID-19 on the Taiwanese tourism industry, on February 13, 2020, the Taiwanese government proposed the "Relief, Revitalization, and Economic Stimulus Project in Response to the COVID-19 Pandemic," which was worth approximately US\$1.8 billion (Executive Yuan 2020). The implementation directions of this project were released on February 26, 2020. From March 12, 2020, applications began to be received under the aforementioned project. This project offers assistance such as financing, operation assistance, talent cultivation, and salary subsidies for tourism businesses, including travel, lodging, and amusement park businesses. An application can be submitted by an enterprise or the guild or association of a business (Tourism Bureau, MOTC 2020a,2020b).

The aforementioned project offers a talent cultivation subsidy of up to US\$677 per person and is available to approximately 90,000 employees of 3500 hotel enterprises in Taiwan (employees taking a talent cultivation course receive US\$5.6 per hour, and they can take up to $120 \mathrm{~h}$ of courses). It also offers financing and operation subsidies to hotel operators (Tourism Bureau, MOTC 2020a). The talent cultivation subsidy had an original budget of US\$17.85 million; however, this amount was eventually increased fourfold to US\$71.43 million. Because the allotted funds were exhausted, the Taiwanese government ceased to accept applications for the project on June 12, 2020. A hotel offered the first talent cultivation course in late March 2020. According to the open data released by the Taiwanese government on June 4, 2020, subsidies were approved for 642 talent cultivation courses for training 86,070 
people. The lodging industry accounted for 160 of these courses, whereas other guilds and associations accounted for 317 courses (Tourism Bureau, MOTC 2020c).

Regarding the training arrangement for courses funded by the talent cultivation subsidy, a class could accommodate not more than 80 students and had to be conducted on consecutive days (up to a total of 15 days). An enterprise could arrange for each employee to attend only one training course under the government salary subsidy. Larger enterprises with numerous employees had more people who could participate in the courses. Consequently, the larger an enterprise whose applications were accepted, the higher the subsidies it received (Tourism Bureau, MOTC 2020d). The objective of the stimulus project was to replace relief with training to enable tourism-related industries to retain employees and reduce the impact of the COVID19 pandemic on the Taiwanese tourism and hospitality industry.

Several studies have examined whether working in various businesses during a pandemic provides security. For example, Sönmez et al. (2020) reported that the physical and mental health of hotel and restaurant employees of an immigrant background in the USA may have been affected by the stress of being laid off due to COVID-19. Filimonau et al. (2020) investigated high-level managers of the lodging industry in Spain and discovered that during the COVID-19 pandemic, the flexibility of the manager's enterprise affected how secure they perceived their job to be, which further affected whether they wanted to remain in their post. Therefore, the flexibility of an enterprise when facing a crisis (e.g., being able to seek financial subsidies immediately) and the offering of training to bolster employees' skills are conducive to job stability and security.

Applications for the talent cultivation subsidy of the Taiwanese government could be made for 3 months (March to June 2020). The cultivation courses held by enterprises, guilds, and associations were held over approximately 5 months (March to August 2020). The conducting of training sessions during regular operation resulted in numerous employees being unable to participate in these sessions because they were working. Moreover, under normal circumstances, training is often arranged in accordance with employees' rank. Unified training for all employees regardless of their rank is rarely conducted. However, because the COVID-19 pandemic affected their business, hotels did not layoff employees or force them to take unpaid leave when the number of customers was low. Rather, they applied for the government subsidy and arranged for employees of all ranks to receive the same training. Given this background, the feelings of hotel employees who received subsidy-enabled training merit investigation.

On the basis of the training effectiveness evaluation model proposed by Kirkpatrick (Kirkpatrick and Kirkpatrick 2016), this study examined the perceptions of Taiwanese hotel employees who received subsidy-enabled training regarding the training's effectiveness under varying conditions (e.g., different departments, job levels, and number of training days). Studies on the lodging industry have verified the advantages of cross-departmental training and cross-training, which positively affect work performance and employee retention (Chen and Tseng 2012; Salem and Abdien 2017). However, theoretical gaps exist in research on training effectiveness evaluation that considers the differences in employees' departments, job levels, and numbers of training days. The training effectiveness evaluation model proposed by 
Kirkpatrick in the 1950s has been subsequently revised continually (Kirkpatrick and Kirkpatrick 2016). Studies have proposed the use of the Kirkpatrick model with a clear evaluation hierarchy structure (Falletta 1998; Moldovan 2016). The Kirkpatrick model has been applied in the fields of nursing (Bhatia et al. 2020) and vocational education (Sakthi and Moshi 2021). However, this model has rarely been used to evaluate the training of hotel employees.

Therefore, the current study investigated the perceptions of Taiwanese employees who participated in subsidy-enabled training regarding the effectiveness of the training for lodging industry enterprises that had their talent cultivation application accepted. By understanding the implementation of the talent cultivation project, we could determine how its implementation benefited industry workers.

The rest of this paper is structured as follows: Section 2 presents the literature review and proposed hypotheses. Section 3 describes the study methodology. Section 4 presents the study results. Finally, Sect. 5 provides the conclusions, implications, and limitations of this research and recommendations for future research.

\section{Literature review and hypothesis development}

\subsection{Lodging industry in Taiwan}

\subsubsection{Taiwan's lodging industry and its developmental background}

The lodging industry in Taiwan is divided into two categories: tourist hotel enterprises and hotel enterprises. According to the Act for the Development of Tourism, tourist hotel enterprises comprise international and regular tourist hotels. Tourist hotel enterprises are for-profit enterprises that provide tourists with accommodation and related services for a brief period (Laws \& Regulations Database of the Republic of China 2020).

Taiwan's tourist hotels began to be developed in 1956, and their purpose was to receive foreign guests. Subsequently, the government gradually established and amended regulations on the operation and management of tourist hotels. In the 1960s and 1970s, relatively large hotels were developed in Taiwan and international hotel brands entered the nation. In the mid-1970s, a global energy crisis occurred and the government banned hotel construction. Consequently, in the late 1970s, insufficient tourist hotels were available to receive international travelers. The Taiwanese government then established clear standards for the facilities offered by and operational scope of tourist hotels. It also formulated regulations to encourage the construction of and investment in tourist hotels. The Act for the Development of Tourism, which serves as the legal basis for Taiwanese tourist hotels, was enacted in 1980. This act clearly defined a tourist hotel, its operational scope, the permitted systems in it, and all relevant penalties. In the 1990s, the Taiwanese government proposed various acts to encourage investment in and the upgrade of the Taiwanese lodging industry (Tourism Bureau, MOTC 2020e). Before 1985, regulation of Taiwan's lodging industry was performed by the police. Later, after the government had changed the regulations, the lodging industry was administered by the tourism 
department of each city and county. Since 1990, the Taiwanese government has supervised local tourism units to reinforce the management of the lodging industry, thereby ensuring the systematic operation of this industry (Tourism Bureau, MOTC 2020e).

\subsubsection{Operation of Taiwan's lodging industry}

The earliest open data on tourist hotel operations provided by the Taiwanese government are from 1990. In that year, the number of tourist hotels in Taiwan was 90, their mean annual occupancy rate was $57.85 \%$, their mean room rate was approximately US\$85, and their total annual operation income was approximately US\$760 million. From 1990 to 2019, relevant operation figures for Taiwanese tourist hotels mostly increased. The mean occupancy rate has remained at approximately $60 \%$. From 1995 to 2015, the main operation income of tourist hotels came from dining rather than accommodation or room services. However, over time, the dining income and guest room income gradually became equally important. In 2019, Taiwan had 127 tourist hotels; their mean room rate was approximately US\$125 and annual turnover was nearly US\$2 billion (Executive Information System, Tourism Bureau, MOTC 2020a).

The earliest available and comprehensive electronic open data on the lodging industry are from 2010. In 2010, the number of legally registered hotels in Taiwan was 2687 , their mean annual occupancy rate was $43.19 \%$, their mean room rate was approximately US\$60, and their annual operation income was approximately US\$1.2 billion. Since 2010, the number of hotels has increased and the occupancy rate has remained at approximately 50\%. In 2019, the number of hotels in Taiwan was 3370 and their total annual operation income was approximately US\$3 billion. The hotel room rents for the majority of the operation income of most Taiwanese tourist hotels (Executive Information System, Tourism Bureau, MOTC 2020b) (Table 1).

The guests visiting Taiwanese tourist hotels are mostly independent tourists (67\%) of whom $45 \%$ are Taiwanese. Among foreign guests, approximately $43 \%$ are from Asia (Executive Information System, Tourism Bureau, MOTC 2020a). No relevant information is available on the guest characteristics for Taiwanese hotels. In response to the COVID-19 pandemic, various countries partially closed their borders. Thus, tourist hotels in Taiwan could not retain their number of foreign guests, who previously accounted for $55 \%$ of their total guests. Thus, Taiwanese tourist hotels had only Taiwanese guests and had to share the market with other Taiwanese hotels.

\subsection{Taiwan's lodging industry under COVID-19}

\subsubsection{Effect of the COVID-19 pandemic on the Taiwanese lodging industry}

The COVID-19 pandemic began in December 2019, and countries worldwide subsequently began to close their borders, place restrictions on gatherings, and implement rules related to social distancing. Most guests of the Taiwanese tourist hotel industry 


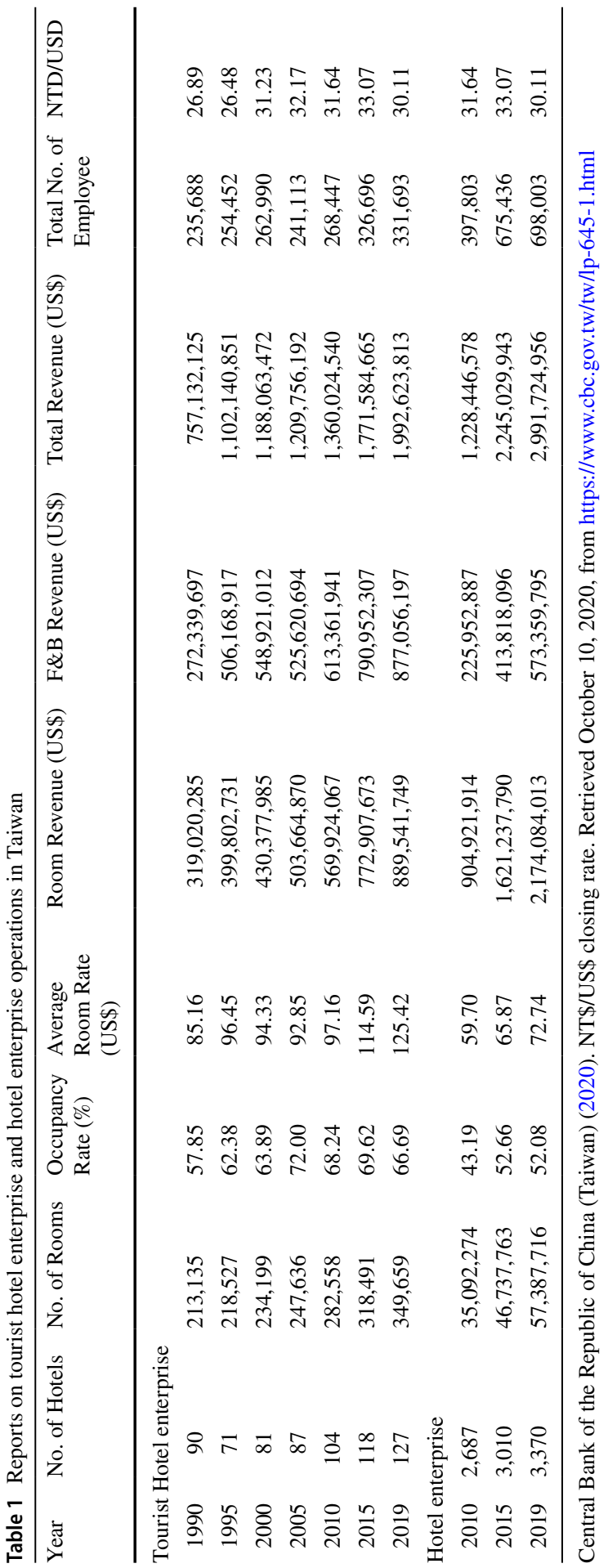


are foreigners (approximately 55\%); therefore, this industry was directly affected by the COVID-19 pandemic. In 2019, the aforementioned industry's annual operation income was approximately US\$2.07 billion (US\$920 million from room income and US\$910 million from dining income). However, after the first COVID-19 case was detected in Taiwan in late January 2020, the operation income of tourist hotels declined compared with the same period in 2019. In April 2020, the occupancy rate of Taiwanese tourist hotels was down to $15 \%$, which was only $22 \%$ of the occupancy for the same period in 2019. According to the most recent information released by the government, room operation income was approximately US\$200 million from January to June 2020 , which was $44 \%$ of that in the same period in 2019. Operation income from dining was also affected. In the first half of 2020, this income was $66 \%$ of that for the same period in 2019. The number of employees also declined each month in the first half of 2020. In June 2020, the number of employees in the Taiwanese tourist hotel industry was 14\% fewer than in January 2020 (Executive Information System, Tourism Bureau, MOTC 2020a). Thus, Taiwanese tourist hotels were considerably affected by the COVID-19 pandemic (Table 2).

The Taiwanese hotel industry's turnover in 2019 was US\$3.1 billion (US\$2.3 billion from rooms and US\$600 million from dining). In January 2020, its occupancy rate was $46 \%$, which was not substantially different from that during the same period in 2019 (49.6\%). However, the occupancy rate decreased considerably after February 2020. In April 2020, the occupancy rate was only $20.27 \%$, which was $37.6 \%$ of that in the same period in 2019. Room rates accounted for most of the income of the hotel industry. Because countries shut their borders due to the COVID-19 pandemic, Taiwanese hotels had only Taiwanese guests, and these hotels had to share the market with tourist hotels. The most recent data reveal that in the first half of 2020 , the room operation income of Taiwanese hotels was approximately US\$630 million, which was $57 \%$ of that in the same period in 2019. The operation income from dining was approximately US\$200 million in the first half of 2020, which was $64 \%$ of that in the same period in 2019 . The hotel industry had approximately $12 \%$ fewer employees in June 2020 than in January 2020 (Executive Information System, Tourism Bureau, MOTC 2020b). Thus, the hotel industry was also affected by the COVID-19 pandemic but not as severely as the tourist hotel industry (Table 3).

\subsubsection{Government subsidy project for industry transformation}

In response to the COVID-19 pandemic, on March 9, 2020, the Taiwanese government released the Directions for the Implementation of Training by the MOTC to Assist in the Transformation of Tourism-Related Industries Affected by Major Pandemics. These directions describe the subsidies for talent cultivation and training in tourism-related industries. Initially, only guilds or associations belonging to tourismrelated industries were permitted to apply; however, the application was later opened to enterprises. A subsidy of US\$5.6 per hour for up to $120 \mathrm{~h}$ was given to a training participant. Subsidies of up to US $\$ 107,000$ could be obtained from one application. Once an application had passed a review, training could be offered. After training had been conducted, relevant documents had to be submitted by businesses to write 


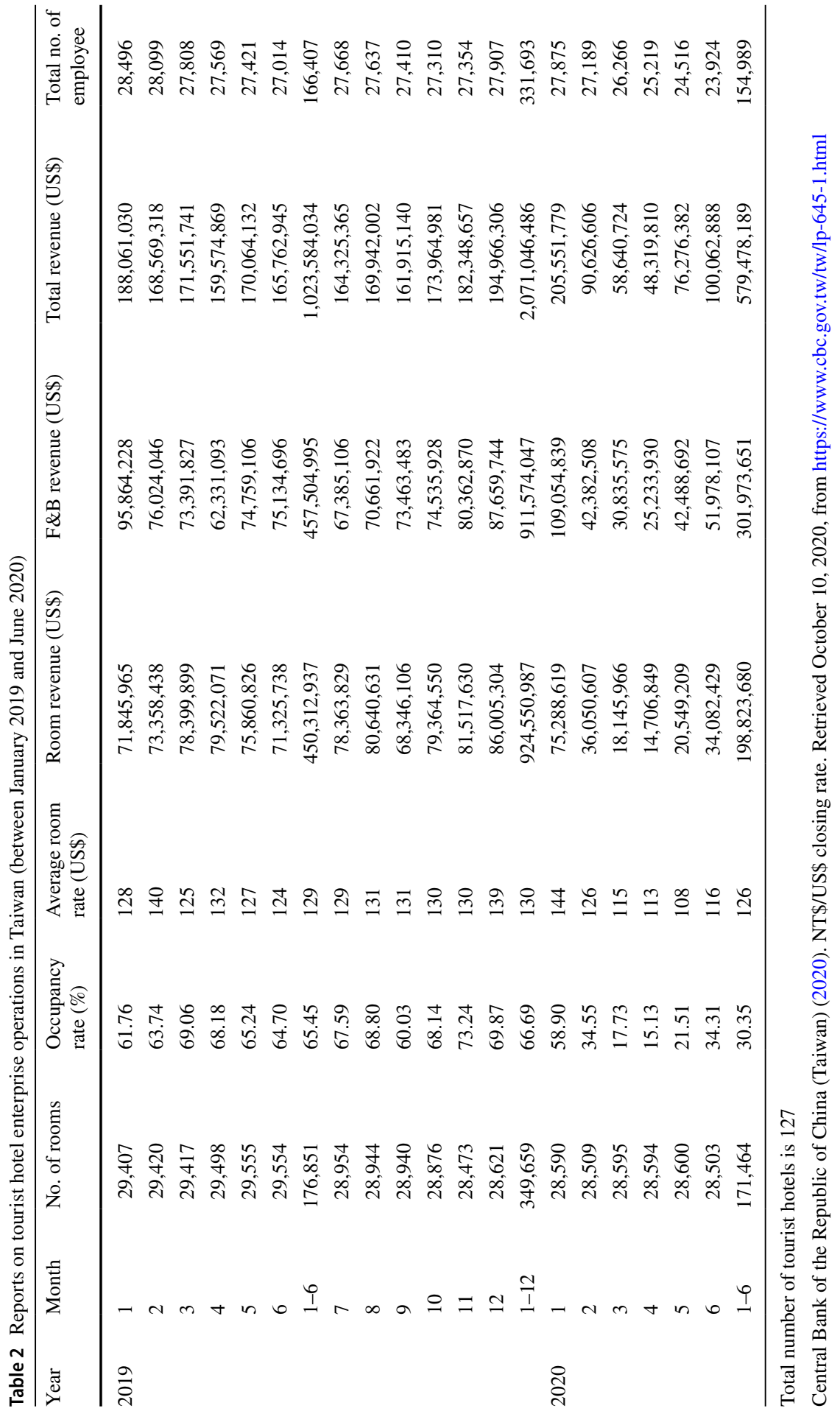




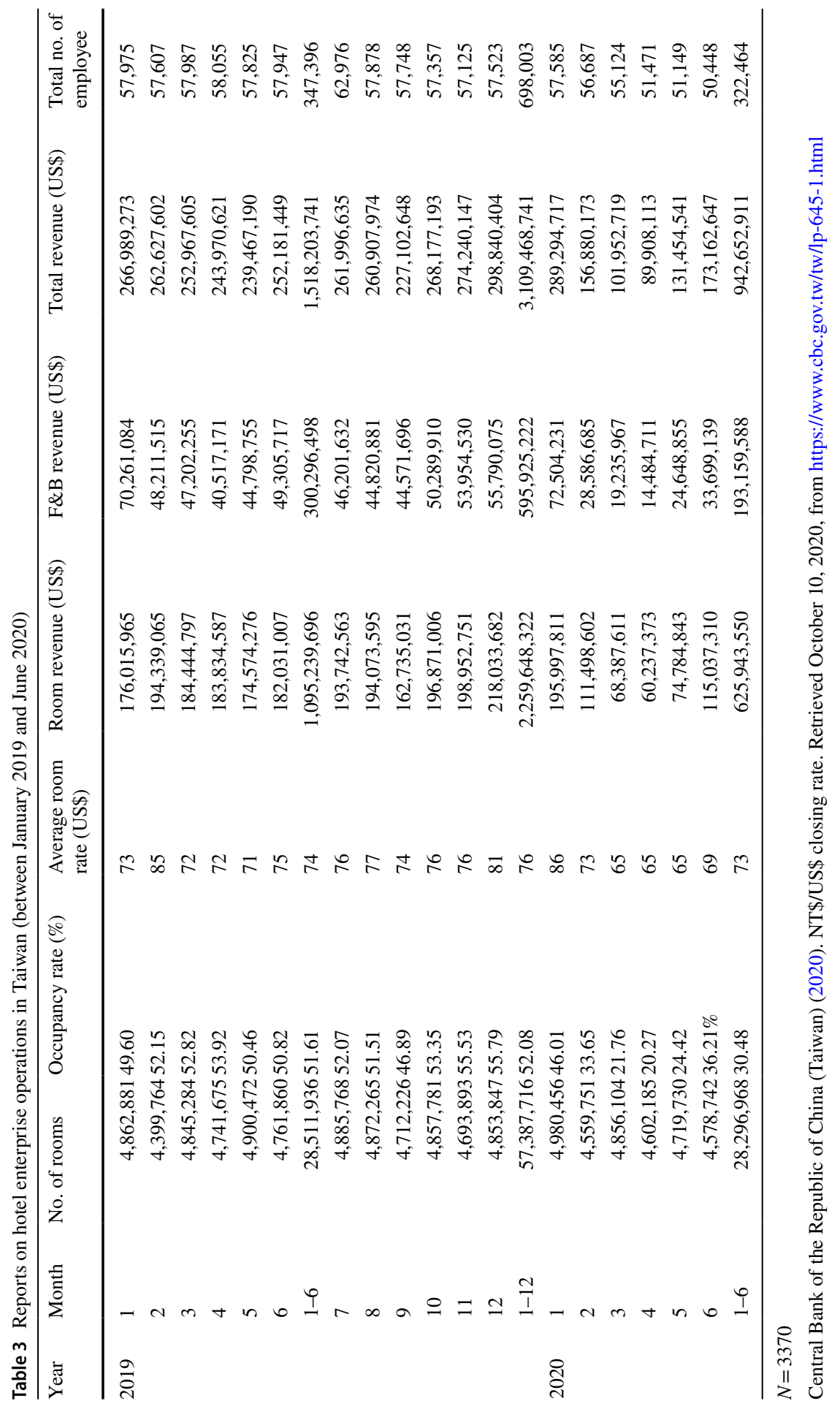


off the cost and receive the subsidy (Relief Package for Tourism and Transportation Amid the COVID-19 Pandemic 2020).

Training courses for talent cultivation and receiving subsidies had to be designed under the following contexts: (1) in-service training, (2) preparation for industry upgrade and service transformation (at least $4 \mathrm{~h}$ of training), (3) safety improvement and protection of travelers' rights, (4) digital and precise marketing (at least $4 \mathrm{~h}$ of training), (5) marketing promotion according to the Taiwanese Tourism Bureau's tourism policies (at least $2 \mathrm{~h}$ of training), (6) connecting to young or new entrepreneurship and improving relevant techniques for local tourism, and (7) cross-regional exchange or benchmark learning (Tourism Bureau, MOTC 2020d). The compulsory elements of these training courses were industry upgrade and service transformation, digital and precise marketing, and tourism policy marketing. Other aspects could be selected and planned by the training units. Each application unit invited various teachers and offered different teaching content.

All hotels that applied for subsidies had to devise training curricula that included the three compulsory courses specified by the government and fulfilled the corresponding teaching hour requirements. In addition, the instructors of these courses were required to possess background knowledge related to the course content; nevertheless, flexibility was allowed in the scope and depth of the course content. When filing for reimbursement, each hotel had to submit information on the course summary, handouts, teaching interaction, and learning assessment to prove that its course content aligned with the topics specified for the compulsory courses. The topics of the three compulsory courses were selected to explore the effect of digital technology on the service industry and the service industry's need for transformation in response to the ongoing COVID-19 pandemic. In addition to the three compulsory courses, other courses were added to the training curriculum depending on the characteristics and development of the hotel (Tourism Bureau, MOTC 2020d). Overall, the curriculum framework of subsidy-enabled employee training was designed to respond to the impact of the COVID-19 pandemic on the hotel industry while allowing hotels to adjust the training course content flexibly.

Applications for the talent cultivation subsidy could be made from mid-March 2020. In late March, the first wave of review results was released for lodging industry organizations and enterprises that offered training. The subsidy budget was expanded to US\$71.43 million. The Taiwanese government ceased to accept applications in mid-June 2020. Training was implemented between March and August 2020 (Tourism Bureau, MOTC 2020c). The duration of the application subsidy was short, and enterprises had to propose training planning immediately, including information on the training content, teachers, training hours, and number of trainees.

\subsection{Training effectiveness}

\subsubsection{Definition of training effectiveness}

Chen and Wang (2006) stated that training effectiveness refers to trainees' perceptions of training course learning, behavioral change, and organizational contribution. 
Moreover, training effectiveness reflects improvements in trainees' knowledge, skills, and performance. Wang (2000) reviewed the literature and reported that training effectiveness refers to a certain standard being employed, either during or after the training process, for systematic analysis and review to assess the value of training and organizational performance. Assessments of training effectiveness can help a training unit understand the value of a training project, help the training unit review whether the training goals have been achieved, and serve as a reference for determining the need for future training (Chen et al. 2012).

\subsubsection{Theories of training effectiveness}

In 1990, Bushnell proposed the input-process-output model, in which training effectiveness assessment is considered a dynamic process that must be investigated from the input, process, and output perspectives. The training effectiveness assessment proposed by Bushnell involved the analysis of short-term output and long-term results. Shortterm output refers to the knowledge and skills obtained to improve work, whereas long-term results refer to increases in an enterprise's profits, customer satisfaction, and organizational productivity (Chen and Wang 2006).

Kirkpatrick developed a four-level training effectiveness evaluation model in 1959 (Kirkpatrick and Kirkpatrick 2016). This model consists of the following four levels: reaction, learning, behavior, and results. The reaction, learning, and behavior levels can be assessed in terms of training satisfaction (TS), personal ability improvement (AI), and level of application at work, respectively. The New World Kirkpatrick Model was proposed in 2009. To create this model, the items of the original four levels of the Kirkpatrick model were redefined to increase the comprehensiveness of the training effectiveness assessment framework (Kirkpatrick and Kirkpatrick 2016). Using the New World Kirkpatrick Model, changes in trainees' reactions, learning, behaviors, and results can be understood. Training effectiveness assessments can help a business understand whether training was successful and reveal possible directions of adjustment for future course planning.

\subsubsection{Variables related to training effectiveness}

Training effectiveness assessment usually involves the assessment of TS, personal AI (learning from training), application in actual work (behavioral change), and training effectiveness (Chen et al. 2012; Wang 2000). TS, personal AI, and application in actual work correspond to the reaction, learning, and behavior levels, respectively, of Kirkpatrick's four-level model. According to Kirkpatrick's theory, only business results (such as profit margin, productivity, and improvement in work performance) obtained 6-12 months after training are relevant; thus, these results must be assessed separately (Chen et al. 2012; Wang 2000). 


\subsection{Research framework and hypotheses}

The current study referred to the framework of the New World Kirkpatrick Model (Kirkpatrick and Kirkpatrick 2016) to develop a training effectiveness assessment model involving reaction, learning, behavior, and results. We also referred to other studies (Chen and Wang 2006; Chen et al. 2012; Chi et al. 2007; Wang 2000) and employed TS (reaction level), personal AI (learning level), and actual application at work (behavioral level) in the research framework. This study investigated the perception of employee trainees immediately after training; thus, the result level in the Kirkpatrick model was not reviewed. The following hypotheses are proposed in this study: (Fig. 1).

H1 The TS of employees undergoing training significantly affects their AI.

H2 The AI of employees undergoing training significantly affects their practical application (PA).

H3 The TS of employees undergoing training significantly affects their PA.

\section{Methodology}

\subsection{Research questionnaire design}

The questionnaire designed in this study comprised two parts, namely those on demographic information and training effectiveness. The demographic information part comprised seven items: items on sex, position level, work location, work department, number of years in the organization, number of years in the industry, and days of training received at the time of completing the questionnaire. The training effectiveness part consisted of nine items assessing TS, five items assessing AI, and seven items assessing PA. This part was scored using a 5-point Likert scale ranging from 1 for strong dissatisfaction or disagreement to 5 for strong satisfaction or agreement.

The research framework was based on the Kirkpatrick model, in which the evaluation items in each hierarchical level are specified but a standard set of questionnaire items is not provided. This study considered the differences between local regions in Taiwan; thus, when designing the questionnaire items, we referenced other Taiwanese studies on training effectiveness. These studies have used the Kirkpatrick model to evaluate training effectiveness (Chen et al. 2012; Wang 2000) and both training effectiveness and TS (Chen and Wang 2006; Chi et al. 2007; Hsieh and Chang 2010). Thus,

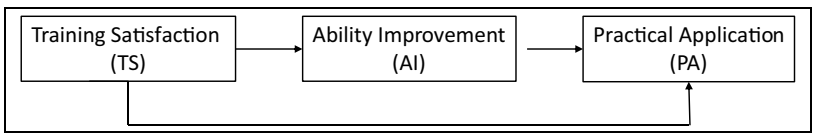

Fig. 1 Research framework 
the questionnaire items used in this study were already in Chinese and did not require translation from other languages.

This study employed items evaluating TS, AI, and PA to assess training effectiveness. The questionnaire items were adapted from the literature (Chen and Wang 2006; Chen et al. 2012; Chi et al. 2007; Hsieh and Chang 2010; Wang 2000). The TS items were used to assess trainees' satisfaction with their training. The AI items were used to measure the degree to which the trainees had absorbed the training course content and the overall change in their knowledge and ability. The PA items were used to assess how well the trainees had applied the knowledge and skills they had acquired to their work.

\subsection{Research participants and sampling}

The participants of this study were hotel employees who participated in subsidyenabled training. These employees volunteered or were sent to participate in training because their training organization (enterprise, guild, or association) had applied to the Taiwanese government's talent cultivation subsidy project and had been accepted.

Regarding the sampling in this study, several points must be noted. First, at the time of writing, a list of successful applications for the project had not been released. Second, the subsidy applications were made between March and June 2020, and the training was conducted from late March to August 2020. Thus, the time from submitting an application to the application being accepted was not fixed; therefore, which hotels were sending employees for training at any particular moment could not be determined. Third, information on the training courses offered by guilds, associations, and hotels was only released to certain groups or within the enterprise. Fourth, because the information regarding successful applications is not open, it could not be determined whether the training courses offered by guilds and associations were attended by employees of multiple hotels. Obtaining participation consent from both the training unit and employer of the trainees within a short period (the training duration ranged from 1 to 15 days) was difficult.

Therefore, this study inquired into which tourist hotels had made successful subsidy applications, gained the consent of the training unit, and conducted a survey in the training sessions attended by the hotel's employees. To ensure that diverse data were obtained, we invited employees participating in six training sessions to complete our questionnaire. Each session comprised approximately 80 trainees, who could decide whether they wished to participate in our study. These six training sessions were held in three major metropolitan areas of Taiwan, namely Taipei, Taichung, and Kaohsiung. We visited the training locations personally to conduct the survey.

\subsection{Questionnaire pretest}

The purposes of a pretest are to confirm that the questionnaire items are clear and have discriminatory ability and to determine the time required to complete the questionnaire. 
Hotel employees who had participated in training were invited to participate in the pretest. A total of 30 valid questionnaires were retrieved. Item analysis was conducted on the 21 training effectiveness items. The independent samples $t$ test and correlation analysis were employed to assess item discrimination. The pretest data were divided into high- and low-score groups (top and bottom 27\%, respectively), and the independent samples $t$ test was then used to identify whether significant differences existed between the groups. The results revealed that all 21 items exhibited satisfactory discrimination; thus, no item had to be removed. This study then analyzed the Pearson's correlations between the total score of the scale and the score of each item. The results revealed that all the items were significant (the correlation coefficients ranged between 0.57 and 0.96), which was in agreement with the finding obtained in the independent samples $t$ test that all items had satisfactory discrimination. The time required to complete the questionnaire was 10-15 min. We confirmed with the participants that the language of each item was clear.

\subsection{Data collection with the formal questionnaire}

The research duration was May to August 2020. We visited the training courses to collect data. Before distributing copies of the questionnaire, we explained to the employees participating in the training that the purpose of the survey was to understand the effectiveness of the training being held under the talent cultivation project of the Taiwanese government and that the survey was independent from the enterprise. We also stated that the survey was anonymous and voluntary. The questionnaire was distributed at the end of the day's training.

\subsection{Data analysis}

The Statistical Package for the Social Sciences (SPSS) and Analysis of Moment Structures (AMOS) software programs were used for statistical analysis. This study conducted the following analyses in sequence: questionnaire item discrimination analysis (i.e., item analysis), reliability analysis, descriptive statistics analysis, difference analysis (i.e., the independent samples $t$ test and analysis of variance [ANOVA]), correlation analysis, and path analysis. In the ANOVA, the Scheffe post hoc test was used for intergroup analysis because the numbers of participants in the two groups were different. To test the research hypotheses and the causal effects among the three considered variables, this study first conducted correlation analysis for understanding the relationships between the variables. Subsequently, structural equation modeling (SEM) was performed to identify the suitable components of each variable and construct the research model, which was used for path analysis. 


\section{Research results}

\subsection{Descriptive data}

The sex ratio among the study participants was 50.00\%:50.00\%. Most of the participants worked in the Greater Taipei area (approximately 63\%). A total of $46.04 \%$ and $35.40 \%$ of the participants worked in the dining and room departments of their hotel, respectively. Regarding their rank, approximately $59 \%$ of the participants were not in management and approximately $20 \%$ were basic-level supervisors. Most of the participants had worked in their hotel for 1-5 years, and more than $50 \%$ of the participants had worked in the hospitality industry for 1-10 years. The number of training days after which they completed the questionnaire ranged from 1 to 8 days. Each training unit held the training for a different duration, and the situation in which the employees participated in the training differed; thus, differences were observed in the participant responses.

According to the data from the Ministry of Labor $(2019,2020)$ of Taiwan, approximately 92,000 people were employed in the Taiwanese lodging industry in July 2019 . Of these people, $85.66 \%$ were in a nonmanagement or professional support post and $14.34 \%$ were a manager or supervisor. High-, middle-, and basic-level managers accounted for approximately $6 \%, 23 \%$, and $72 \%$, respectively, of all the managers and supervisors in the aforementioned industry. The aforementioned data are in line with the data obtained for the sample in this study, in which management-level employees accounted for a relatively high percentage of all trainees $(32.18 \%)$. High-, middle-, and basic-level managers accounted for approximately $7 \%, 31.5 \%$, and $61.5 \%$, respectively, of the trainees in management posts. Most of the study participants were not in a management post $(58.91 \%)$. However, $32.18 \%$ of the participants were in a management post. This value is considerably higher than the percentage of managers in the Taiwanese lodging industry (14.34\%). This result indicates that hotels had assigned a higher proportion of management employees than nonmanagement employees to participate in the talent cultivation training. Middle-level managers account for $23.00 \%$ of management employees in the Taiwanese lodging industry; however, they accounted for $31.54 \%$ of the study participants in a management post. Thus, middle-level managers were more likely to attend the talent cultivation training than were managers at other levels (Table 4).

Training effectiveness was measured in terms of three aspects: TS, AI, and PA. The mean scores for the nine TS items under a 5-point Likert scale were between 4.01 and 4.38. The participants were most and least satisfied with the teachers and number of training sessions, respectively. The mean scores for the five AI items were between 4.04 and 4.17. The participants were most satisfied with the improvement in their interpersonal relationship and communication skills. Finally, the mean scores of the seven PA items were between 4.04 and 4.17, with the highest score given to "helping self-growth" (Table 5).

Table 6 presents the score distribution of the 21 items under the adopted 5 -point scale. The minimum and maximum scores of the items were 1 and 
Table 4 Demographic information of the research participants

\begin{tabular}{|c|c|c|c|c|c|}
\hline & Frequency & $\%$ & & Frequency & $\%$ \\
\hline \multicolumn{3}{|l|}{ Sex } & \multicolumn{3}{|l|}{ Department } \\
\hline Male & 202 & 50.00 & Dining department & 186 & 46.04 \\
\hline \multirow[t]{2}{*}{ Female } & 202 & 50.00 & Room department & 143 & 35.40 \\
\hline & & & Logistics department & 75 & 18.56 \\
\hline Region & & & \multicolumn{3}{|l|}{ Rank } \\
\hline Greater Taipei & 256 & 63.37 & Nonmanagement post & 238 & 58.91 \\
\hline Taichung & 29 & 7.18 & Basic-level manager & 80 & 19.80 \\
\hline Kaohsiung & 54 & 13.27 & Middle-level manager & 41 & 10.15 \\
\hline \multirow[t]{2}{*}{ Other } & 65 & 16.09 & High-level manager & 9 & 2.23 \\
\hline & & & $\begin{array}{l}\text { Administration and logistics employ- } \\
\text { ees }\end{array}$ & 36 & 8.91 \\
\hline \multicolumn{3}{|c|}{ Number of years in their organization } & \multicolumn{3}{|l|}{ Number of years in the industry } \\
\hline Less than 1 year & 23 & 5.69 & Less than 1 year & 14 & 3.47 \\
\hline $1-5$ years & 202 & 50.00 & $1-5$ years & 152 & 37.62 \\
\hline $6-10$ years & 84 & 20.79 & $6-10$ years & 86 & 21.29 \\
\hline $11-15$ years & 36 & 8.91 & $11-15$ years & 48 & 11.88 \\
\hline $16-20$ years & 22 & 5.45 & $16-20$ years & 46 & 11.39 \\
\hline 21 years or more & 37 & 9.16 & 21 years or more & 58 & 14.36 \\
\hline \multicolumn{6}{|c|}{ Number of days of training received on the day of questionnaire completion } \\
\hline 1st day & 127 & 31.44 & 5th day & 14 & 3.47 \\
\hline 2nd day & 31 & 7.67 & 6th day & 72 & 17.82 \\
\hline 3rd day & 25 & 6.19 & 7th day & 63 & 15.59 \\
\hline 4th day & 41 & 10.15 & 8th day & 31 & 7.67 \\
\hline
\end{tabular}

$N=404$

Region refers to working location. Other includes Taoyuan, Hsinchu, and Kenting

Regarding department, (A) the dining department includes the front of the house and kitchen; (B) the room department includes customer service, room service, booking, phone operation, meetings, laundry, and fitness facilities; (C) administration and logistics units include human resources, finance, sales, marketing and public relations, procurement, engineering, information, security, and parking management

Regarding rank, (A) nonmanagement post means that the employees were not managers (such as servers and operators); (B) basic-level managers were chiefs and forepersons; (C) middle-level managers were managers and deputy managers; (D) high-level managers were directors and inspectors; and (E) administration and logistics employees were nonmanagement workers

5 , respectively. Of the nine items related to $\mathrm{TS}$, more than $50 \%$ of the participants assigned a score of 5 to TS05, TS06, and TS08; however, only $37.62 \%$ and $39.36 \%$ of the participants assigned this score to TS01 and TS02. Of the five items related to AI, $37.38 \%$ of the participants assigned a score of 5 to AI01 and AI02. More than $40 \%$ of the participants assigned this score to the remaining three items related to AI. Of the seven items related to PA, more than $40 \%$ of the participants assigned a score of 5 to PA03, PA06, and PA07.

Each training unit found teachers itself to conduct the talent cultivation courses; thus, the teachers at each training unit differed. The study participants 
Table 5 Descriptive statistics of the training effectiveness variables

\begin{tabular}{lll}
\hline Training effectiveness & Mean & SD \\
\hline Training Satisfaction, TS & & \\
TS01 Training duration & 4.10 & 0.90 \\
TS02 Number of training sessions & 4.01 & 0.96 \\
TS03 Course content (course type) & 4.13 & 0.88 \\
TS04 Teaching material content & 4.22 & 0.85 \\
TS05 Teachers & 4.38 & 0.81 \\
TS06 Location & 4.27 & 0.90 \\
TS07 Equipment & 4.25 & 0.87 \\
TS08 Interaction among trainees & 4.24 & 0.96 \\
TS09 Overall satisfaction & 4.24 & 0.85 \\
Ability Improvement, AI & & \\
AI01 Professional knowledge & 4.06 & 0.91 \\
AI02 Knowledge in management & 4.04 & 0.91 \\
AI03 Interpersonal relationships \& communication skills & 4.17 & 0.84 \\
AI04 Work attitude and confidence & 4.12 & 0.87 \\
AI05 Overall absorption of what was taught & 4.11 & 0.88 \\
Practical Application, PA & & \\
PA01 Professional knowledge & 4.02 & 0.94 \\
PA02 Knowledge in management & 4.02 & 0.92 \\
PA03 Interpersonal relationships \& communication skills & 4.12 & 0.86 \\
PA04 Work attitude and confidence & 4.10 & 0.89 \\
PA05 Application of new skills & 4.06 & 0.93 \\
PA06 Helping self-growth & 4.20 & 0.86 \\
PA07 Increased professional skills and knowledge & 4.19 & 0.91 \\
\hline
\end{tabular}

$N=404$

The items were scored using a 5-point Likert scale, with 1 denoting strong dissatisfaction/very unimportant and 5 denoting strong satisfaction/very important

were relatively satisfied with their teachers in the talent cultivation training. Regarding the training locations, this study sampled special training courses held by tourist hotels. Because most of the training was conducted within these hotels, the trainees did not have to travel to receive training. With regard to AI, most classes had 80 students who were from different departments and of different ranks. During the courses, they had the opportunity to discuss and interact with others, thereby improving their interpersonal and communication skills. Moreover, because the participants completed the training and tasks within the course, their confidence regarding their work was strengthened. Finally, with regard to PA, the participants found that the training course helped their selfgrowth and improved their professional skills and knowledge. In addition, the participants found that the application of what they had learned in class helped their self-growth. 
Table 6 Descriptive statistics of the training effectiveness variables

\begin{tabular}{|c|c|c|c|c|c|c|c|c|c|c|}
\hline \multirow{2}{*}{$\begin{array}{l}\text { Training } \\
\text { effectiveness }\end{array}$} & \multicolumn{2}{|l|}{1} & \multicolumn{2}{|l|}{2} & \multicolumn{2}{|l|}{3} & \multicolumn{2}{|l|}{4} & \multicolumn{2}{|l|}{5} \\
\hline & Count & $\%$ & Count & $\%$ & Count & $\%$ & Count & $\%$ & Count & $\%$ \\
\hline \multicolumn{11}{|c|}{ Training Satisfaction, TS } \\
\hline TS01 & 6 & 1.49 & 9 & 2.23 & 84 & 20.79 & 146 & 36.14 & 159 & 39.36 \\
\hline TS02 & 7 & 1.73 & 14 & 3.47 & 98 & 24.26 & 133 & 32.92 & 152 & 37.62 \\
\hline TS03 & 4 & 0.99 & 7 & 1.73 & 90 & 22.28 & 136 & 33.66 & 167 & 41.34 \\
\hline TS04 & 3 & 0.74 & 6 & 1.49 & 77 & 19.09 & 133 & 32.92 & 185 & 45.79 \\
\hline TS05 & 4 & 0.99 & 4 & 0.99 & 48 & 11.88 & 125 & 30.94 & 223 & 55.20 \\
\hline TS06 & 5 & 1.24 & 10 & 2.48 & 65 & 16.09 & 116 & 28.71 & 208 & 51.49 \\
\hline TS07 & 4 & 0.99 & 5 & 1.24 & 75 & 18.56 & 123 & 30.45 & 197 & 48.76 \\
\hline TS08 & 8 & 1.98 & 12 & 2.97 & 66 & 16.34 & 108 & 26.73 & 210 & 51.98 \\
\hline TS09 & 4 & 0.99 & 6 & 1.49 & 66 & 16.34 & 140 & 34.65 & 188 & 46.53 \\
\hline \multicolumn{11}{|c|}{ Ability Improvement, AI } \\
\hline AI01 & 4 & 0.99 & 17 & 4.21 & 82 & 20.30 & 150 & 37.13 & 151 & 37.38 \\
\hline $\mathrm{AI} 02$ & 3 & 0.74 & 13 & 3.22 & 101 & 25.00 & 136 & 33.66 & 151 & 37.38 \\
\hline AI03 & 2 & 0.50 & 9 & 2.23 & 73 & 18.07 & 153 & 37.87 & 167 & 41.34 \\
\hline AI04 & 2 & 0.50 & 9 & 2.23 & 91 & 22.52 & 138 & 34.16 & 164 & 40.59 \\
\hline AI05 & 3 & 0.74 & 11 & 2.72 & 86 & 21.29 & 141 & 34.90 & 163 & 40.35 \\
\hline \multicolumn{11}{|c|}{ Practical Application, PA } \\
\hline PA01 & 4 & 0.99 & 21 & 5.20 & 85 & 21.04 & 146 & 36.14 & 148 & 36.63 \\
\hline PA02 & 6 & 1.49 & 12 & 2.97 & 95 & 23.51 & 146 & 36.14 & 145 & 35.89 \\
\hline PA03 & 2 & 0.50 & 9 & 2.23 & 91 & 22.52 & 140 & 34.64 & 162 & 40.10 \\
\hline PA04 & 5 & 1.24 & 8 & 1.98 & 88 & 21.78 & 144 & 35.64 & 159 & 39.36 \\
\hline PA05 & 6 & 1.49 & 18 & 4.46 & 74 & 18.23 & 155 & 38.37 & 151 & 37.38 \\
\hline PA06 & 5 & 1.24 & 7 & 1.73 & 65 & 16.09 & 154 & 38.12 & 173 & 42.82 \\
\hline PA07 & 7 & 1.73 & 9 & 2.23 & 65 & 16.09 & 142 & 35.15 & 181 & 44.80 \\
\hline
\end{tabular}

$N=404$

The items were scored using a 5-point Likert scale, with 1 denoting strong dissatisfaction/very unimportant and 5 denoting strong satisfaction/very important

\subsection{Results of difference testing}

No significant differences were found between men and women and between different groups with different years of experience in the organization or lodging industry; however, significant differences were observed between different work regions, departments, ranks, and numbers of training days. Although significant differences in multiple items related to the three variables were found between different work regions and numbers of training days, within-group differences in the post hoc test were noted only for a few TS and PA items.

Participants from "other" regions, middle-level managers, and those on their first day of training assigned higher scores to the TS items than did the other participants. Specifically, compared with the participants from Taipei, the participants from other 
regions were more satisfied with their course $(F=3.86, p<0.05)$, with the teaching materials $(F=5.27, p<0.01)$, and overall $(F=5.16, p<0.01)$. Taipei is the capital of Taiwan; thus, it has more resources than do other regions in Taiwan. Consequently, the participants from Taipei may have had higher expectations of the training than did the participants from other regions. Compared with the managers of other levels, the middle-level managers were more satisfied with the training duration $(F=4.06$, $p<0.01)$ and number of training sessions $(F=5.66, p<0.01)$. Compared with basiclevel managers, who are usually busy with on-site operations, and high-level managers, who have rich operation experience, middle-level managers have higher expectations of training, which indicates that middle-level managers wish to apply what they learn in training to their work $(F=3.39, p<0.05$; i.e., the knowledge related to management in PA). Compared with the other participants, the participants who answered the questionnaire after their first day of training were more satisfied with their interaction with the other trainees $(F=3.65, p<0.01)$ and reported higher overall satisfaction $(F=2.39, p<0.05)$. The participants from Taichung exhibited higher scores on items related to PA than did the workers from Taipei. Those working in the dining department assigned higher scores to knowledge related to management in PA $(F=5.15, p<0.01)$ than did those working in the logistics department $(F=3.39, p<0.05)$. Moreover, middle-level managers assigned higher scores to the aforementioned item than did nonmanagement participants $(F=4.11, p<0.01)$.

\subsection{Results of hypothesis testing}

Pearson's correlation coefficient was used to understand the correlations between the three research variables. The results indicated that all the variable pairs were significantly correlated, with the coefficients being $0.79,0.76$, and 0.89 for TS and AI, TS and PA, and AI and PA, respectively. SEM was used to construct the research model, and path analysis was employed to assess the research hypotheses. First, we conducted confirmatory factor analysis. In accordance with the results of confirmatory factor analysis, the number of items related to TS, AI, and PA were reduced from 9,5 , and 7 , respectively, to 4,4 , and 5 . The items remaining after elimination were used to establish the research framework model $\left(\chi^{2}=182.05\right.$, degrees of freedom $[\mathrm{df}]=62, p<0.01)$. Because the $p$ value in the chi-squared test was smaller than 0.01 , we performed the Bollen-Stine $p$ value correction. The obtained Bollen-Stine bootstrap $p$ value of 0.01 indicated that the chi-squared $p$ value was significant due to a large sample. The overall model fit results revealed that the overall model fit was acceptable (Table 7). The causal model of training effectiveness (PA) fit the collected data; thus, the path analysis model was supported.

The path coefficients obtained through path analysis indicated that the explained variance was 0.88 when TS was used to explain AI, 0.80 when AI was used to explain PA, and only 0.14 when TS was employed to explain PA. When further examining the effects of the variables in the path analysis, we found that TS had a direct significant effect on AI and that AI had a direct significant effect on PA. The total effect of TS on PA was 0.84 and comprised a direct effect (size $=0.14$ ) from TS to PA and an indirect effect $($ size $=0.70)$ from TS to AI and then to PA (Table 8). 
Table 7 Difference test results

\begin{tabular}{|c|c|c|c|c|}
\hline & Region & Department & Rank & Number of days of training \\
\hline \multicolumn{5}{|c|}{ Training Satisfaction, TS } \\
\hline TS01 & N.S & N.S & $F=4.06^{* *}(\mathrm{C}>\mathrm{E})$ & N.S \\
\hline TS02 & N.S & N.S & $F=5.66^{* *}(\mathrm{C}>\mathrm{B}, \mathrm{E})$ & N.S \\
\hline TS03 & $F=3.86 *(\mathrm{D}>\mathrm{A})$ & N.S & N.S & N.S \\
\hline TS04 & $F=5.27 * *(\mathrm{D}>\mathrm{A})$ & N.S & N.S & $F=2.13 *($ N.S. $)$ \\
\hline TS05 & N.S & N.S & N.S & \\
\hline TS06 & N.S & N.S & N.S & $F=2.44 *($ N.S. $)$ \\
\hline TS07 & N.S & N.S & N.S & $F=2.32 *($ N.S. $)$ \\
\hline TS08 & $F=3.64 *($ N.S. $)$ & N.S & N.S & $F=3.65^{* *}(\mathrm{~A}>F)$ \\
\hline TS09 & $F=5.16^{* *}(\mathrm{D}>\mathrm{A})$ & N.S & N.S & $F=2.39 *(\mathrm{~A}>F)$ \\
\hline \multicolumn{5}{|c|}{ Ability Improvement, AI } \\
\hline AI01 & N.S & N.S & N.S & N.S \\
\hline $\mathrm{AIO2}$ & N.S & N.S & N.S & N.S \\
\hline AI03 & $F=3.55^{*}(\mathrm{~N} . \mathrm{S})$. & N.S & N.S & N.S \\
\hline AI04 & $F=3.11 *($ N.S. $)$ & N.S & N.S & N.S \\
\hline AI05 & $F=4.07 * *($ N.S. $)$ & N.S & N.S & N.S \\
\hline Overall AI & $F=3.09 *($ N.S. $)$ & N.S & N.S & N.S \\
\hline \multicolumn{5}{|c|}{ Practical Application, PA } \\
\hline PA01 & $F=4.16^{* *}(\mathrm{~N} . \mathrm{S})$. & N.S & $F=2.39^{*}$ & $F=3.73 * *($ N.S. $)$ \\
\hline $\mathrm{PA} 02$ & $F=4.59 * *($ N.S. $)$ & $F=3.39 *(\mathrm{~A}>\mathrm{C})$ & $F=4.11^{* *}(\mathrm{C}>\mathrm{A})$ & $F=3.57 * *($ N.S. $)$ \\
\hline PA03 & $F=2.98 *($ N.S. $)$ & N.S & N.S & $F=2.47 *(\mathrm{~N} . \mathrm{S})$. \\
\hline PA04 & N.S & $F=3.42^{*}($ N.S. $)$ & N.S & $F=2.52 *(\mathrm{~N} . \mathrm{S})$. \\
\hline PA05 & $F=5.15^{* *}(\mathrm{~B}>\mathrm{A})$ & N.S & $F=2.66^{*}(\mathrm{~N} . \mathrm{S})$. & $F=2.59 *(\mathrm{~N} . \mathrm{S})$. \\
\hline PA06 & N.S & N.S & N.S & N.S \\
\hline PA07 & N.S & N.S & N.S & N.S \\
\hline Overall PA & $F=3.98 * *($ N.S. $)$ & N.S & $F=2.59 *($ N.S. $)$ & $F=2.85^{*}($ N.S. $)$ \\
\hline
\end{tabular}

$N=404$

Overall $\mathrm{AI}=$ mean of the five $\mathrm{AI}$ items; overall $\mathrm{PA}=$ mean of the seven PA items

Region: $\mathrm{A}=$ Taipei, $\mathrm{B}=$ Taichung, $\mathrm{C}=$ Kaohsiung, and $\mathrm{D}=$ other

Department: $\mathrm{A}=$ dining department, $\mathrm{B}=$ room department, and $\mathrm{C}=$ administration and logistics department

Rank: $\mathrm{A}=$ nonmanagement post, $\mathrm{B}=$ basic-level manager, $\mathrm{C}=$ middle-level manager, $\mathrm{D}=$ high-level manager, and $\mathrm{E}=$ administration and logistics nonmanagement post

Number of days of training: $\mathrm{A}=1$ st day, $\mathrm{B}=2$ nd day, $\mathrm{C}=3 \mathrm{rd}$ day, $\mathrm{D}=4$ th day, $\mathrm{E}=5$ th day, $F=6$ th day, $\mathrm{G}=7$ th day, and $\mathrm{H}=8$ th day

Gray cells indicate significance and an intergroup significant difference

N.S. nonsignificant

$* p<0.05 ; * * p<0.01$ 
Table 8 Overall research model and the model fit results

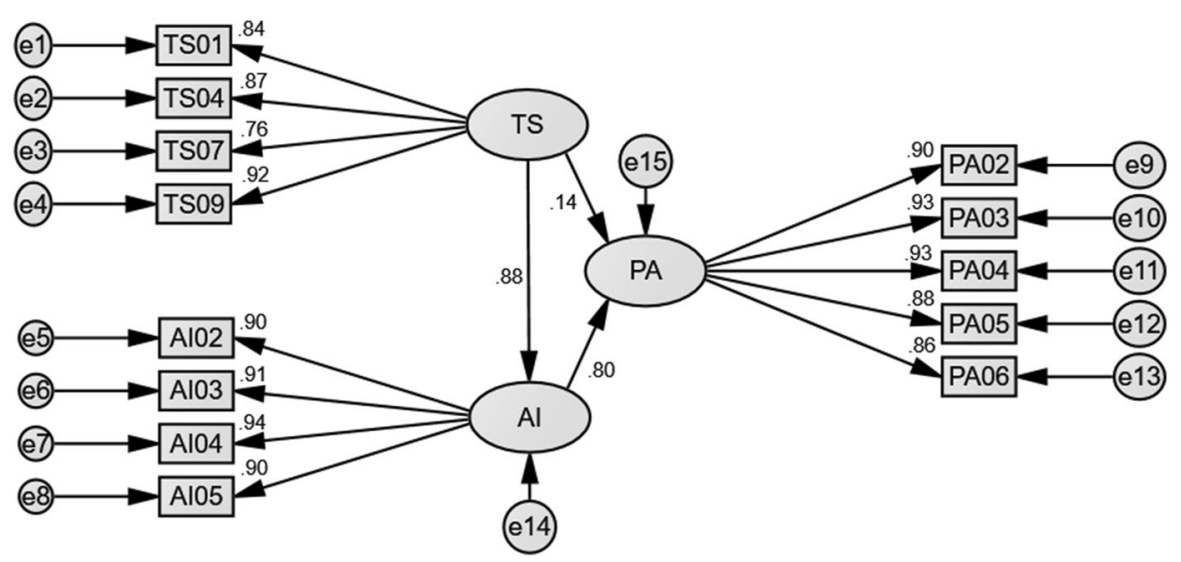

Chi square $=182.05, \mathrm{df}=62, p<0.01($ Bollen-Stine Bootstrap $p=0.01)$

\begin{tabular}{lllll}
\hline Model fit assessment & & & & \\
\hline & Index & $\begin{array}{l}\text { Recommenda- } \\
\text { tion value }\end{array}$ & $\begin{array}{l}\text { Goodness of fit in } \\
\text { this study }\end{array}$ & Result check \\
\hline Absolute fit measure indices & RMR & $<0.05$ & 0.02 & Pass \\
& GFI & $>0.90$ & 0.94 & Pass \\
& AGFI & $>0.90$ & 0.91 & Pass \\
& RMSEA & $<0.08$ & 0.07 & Pass \\
Relative fit indices & NFI & $>0.90$ & 0.97 & Pass \\
& RFI & $>0.90$ & 0.96 & Pass \\
& IFI & $>0.90$ & 0.98 & Pass \\
& TLI & $>0.90$ & 0.98 & Pass \\
Parsimonious fit indices & CFI & $>0.90$ & 0.98 & Pass \\
& PNFI & $>0.50$ & 0.77 & Pass \\
& PGFI & $>0.50$ & 0.64 & Pass \\
& CMIN/DF & $<3.00$ & 2.94 & Pass \\
\hline
\end{tabular}

Path coefficient and effect

\begin{tabular}{llllllll}
\hline Path relations & $\begin{array}{l}\text { Standardized } \\
\text { Regression } \\
\text { Weights }\end{array}$ & S.E & C.R & $p$ & Direct effects & Indirect effects & Total effects \\
\hline $\mathrm{TS} \rightarrow \mathrm{AI}$ & 0.88 & 0.05 & 19.34 & $0.00^{* *}$ & 0.88 & 0.00 & 0.88 \\
$\mathrm{TS} \rightarrow \mathrm{PA}$ & 0.14 & 0.07 & 12.15 & $0.00^{* *}$ & 0.14 & 0.70 & 0.84 \\
$\mathrm{AI} \rightarrow \mathrm{PA}$ & 0.80 & 0.07 & 2.20 & $0.03^{*}$ & 0.80 & 0.00 & 0.80 \\
\hline
\end{tabular}

The recommended values of model fit index were taken from $\mathrm{Wu}$ (2006)

$* p<0.05, * * p<0.01$ 


\section{Research conclusion and suggestions}

\subsection{Conclusion}

The survey conducted in this study revealed that most participants of the talent cultivation programs in Taiwan held nonmanagement posts. Compared with the management-level employees in the Taiwanese lodging industry, these employees accounted for a higher proportion of the participants in the aforementioned programs. Moreover, compared with the middle-level managers among management employees in the Taiwanese lodging industry, middle-level managers accounted for a higher proportion of the management-level participants in the talent cultivation programs. According to the study results, teachers and location were the two TS items that received the highest scores, which indicated that teachers and location were the most satisfying items in the training program to the participants. Moreover, interpersonal relations/communication skills as well as work attitude and confidence were the AI items receiving the highest scores. Help in selfgrowth and improved professional skills and knowledge were the PA items with the highest scores. Farjad (2012) maintained that effective training requires the comprehensive planning and implementation of a training program. Moreover, training effectiveness is high when a course is optimized and meets the demands of the work and organization. Application of the skills and knowledge acquired from training to work and active involvement in learning during training are also critical indicators of learning effectiveness. In the difference analysis of training effectiveness, this study discovered significant between-group (location, department, rank, and number of training days) differences only in TS and PA.

This study established an overall model containing TS, AI, and PA and examined the causal relationships among these variables. TS directly influenced AI, and AI directly influenced PA. Wang (2000) discovered that TS is positively correlated with training content and negatively correlated with training duration. $\mathrm{AI}$ and PA are positively correlated with teachers, the training content, and the training location. In addition, positive correlations exist between TS and AI and between AI and PA. Chen and Wang (2006) also found significant positive correlations among TS, AI, and PA. Kaushal and Srivastava (2021) discovered that when facing a pandemic, industry employees must strengthen their skills, which can be achieved through training or rotation among different departments. When employees have diverse skills and the relevant industry is severely affected by a pandemic or some other disruptive event, the employees can be rotated among different departments and continue working. 


\subsection{Research suggestions}

\subsubsection{Effect of government policy on the Taiwanese lodging industry}

The Taiwanese government launched an industry revival and revitalization project to mitigate the impact of the COVID-19 pandemic on the Taiwanese lodging industry. By offering training subsidies, the government stabilized the finances of enterprises in the aforementioned industry and secured work for the enterprises' employees. The subsidized training comprehensively facilitated industry transformation. Large-scale training that is cross-departmental, involves employees of all ranks, and can last up to 15 consecutive days is difficult to implement when a general enterprise wants to maintain its regular operations. The results of this study indicate that employees from Taiwan's lodging industry responded positively to the talent cultivation training and reported it as being effective. Hao et al. (2020) proposed strategies to enable the China lodging industry to face the COVID-19 pandemic. With regard to human resources, this industry must secure the work and salaries of frontline workers, train workers in multiple skills, and seek financial aid from the government. These strategies are in line with the spirit of the talent cultivation subsidies within the industry revival and revitalization project promoted by the Taiwanese government.

Alonso et al. (2020) examined the functioning of the managers of small hotels in response to the COVID-19 pandemic. In the aforementioned study, these managers mentioned that operation and sales require revolution and change, such as understanding the consumption trend among consumers during the pandemic and considering how consumers obtain products from different channels. Hao et al. (2020) mentioned that during the COVID-19 pandemic, hotel services should be diversified and provide multiple options regarding channels. Moreover, hotels should provide products and services that satisfy consumers' changing preferences and habits during the pandemic. Hotels should also use technology to improve service efficiency and quality. The present study suggests that industry transformation-based talent cultivation can continue to be promoted in the Taiwanese lodging industry in response to consumers' behavior and preference changes due to the COVID-19 pandemic. We suggest that the Taiwanese government establish official courses and teacher qualification standards for the Taiwanese lodging industry and assign employees to participate in training to help this industry re-evaluate and adjust its service operation procedures. Directions for course design should include analyzing consumers' behavioral preferences (such as through big data analysis or trend examination) as well as integrating and adjusting resource usage (such as by replanning products and services, re-examining brand and market distinctions, and optimizing costs and financial structure).

\subsubsection{Continuation of industry transformation}

This study discovered that TS, AI, and PA had causal relationships with training effectiveness. From the research framework, we deduced that the TS dimension consisted of satisfaction with training duration, teaching materials, and facilities as well 
as overall satisfaction. The AI and PA dimensions consisted of management knowledge, interpersonal communication, work attitude, and confidence. Management and interpersonal communication are critical aspects of job competency. Studies have indicated that job competencies are the success characteristics required to complete certain work or tasks, and these competencies can be used as the bases of training course planning for an industry (Chouhan and Srivastava 2014; Shum et al. 2018). Therefore, the current study suggests that when an enterprise organizes training, it should design the training on the basis of the job competencies required for employees of different positions and ranks. Course planners should consider how trainees can use the new skills they acquire during training to their work and self-growth. Under the impact of the COVID-19 pandemic, corporate executives may first decide the direction for transformation and then develop various training programs on the basis of department and rank. To promote industry transformation, training can be extended to give different emphasis to each department and rank. Farjad (2012) mentioned that continuing to offer training results in higher training effectiveness.

\subsection{Research implications}

\subsubsection{Government assistance provided to the Taiwanese lodging industry during the COVID-19 pandemic}

According to the Annual Report on Tourism 2019, Taiwan's tourism foreign exchange income in 2018 was US\$13.7 billion. In that year, approximately 11 million people traveled to Taiwan. In 2003, during the severe acute respiratory syndrome (SARS) epidemic, Taiwan's annual tourism foreign exchange income was US\$3 billion, which was only approximately $70 \%$ of that in 2002 (Tourism Bureau, MOTC 2020f). Approximately 55\% of the tourists staying in Taiwan's tourist hotels are foreigners (Executive Information System, Tourism Bureau, MOTC 2020a); thus, a reduction in the number of international travelers has a strong negative effect on the tourism industry in Taiwan. The SARS epidemic began in November 2002 and ended in July 2003 and primarily occurred in the Asia-Pacific region. Compared with the previous year, the number of annual international travelers to Taiwan was $9 \%$ lower in 2003 due to the SARS epidemic. The number of global tourists visiting Taiwan began to increase in the fourth quarter of 2003 (UNWTO 2004). The COVID-19 pandemic began to spread worldwide in December 2019. Compared with the SARS epidemic, which primarily affected Asia, the COVID-19 pandemic has had a more severe impact on global tourism and will involve a longer tourism recovery period. At the time of writing, international travel has not yet opened up completely and the impact of the COVID-19 pandemic on Taiwan's tourist hotel industry continues.

From 2009 to 2019, the occupancy rate of Taiwan's tourist hotels was between 62 and $72 \%$ and the mean room price was US\$92-US\$125. In 2019, approximately 5.92 million Taiwanese people stayed in Taiwanese tourist hotels. This number represents a $7.5 \%$ increase compared with the corresponding number in 2018. Taiwanese tourists account for approximately $45 \%$ of all tourists staying in Taiwanese 
tourist hotels (Executive Information System, Tourism Bureau, MOTC 2020a). The proportion of Taiwanese tourists accounting for the total number of tourists staying in Taiwanese tourist hotels has increased in recent years (2018-2019); however, because of the COVID-19 pandemic, Taiwanese tourists are now the sole guests in Taiwanese tourist hotels. The Taiwanese travel market is now being shared by hotels and tourist hotels. Taiwan's lodging industry is in dire need of upgrade and transformation. In addition to promoting relevant industry subsidies, the Taiwanese government launched a subsidy plan for safe domestic travel (Tourism Bureau, MOTC $2020 \mathrm{~g}$ ). The present study reviewed the talent cultivation subsidy promoted by the Taiwanese government and the effectiveness of the training programs attended by employees. We discovered that hotel employees were positive about and satisfied with the training as well as their resultant AI and PA. This result indicates that during the COVID-19 pandemic, employees in Taiwan's lodging industry have supported the talent cultivation program in their industry and have found it to be beneficial to their work.

\subsubsection{Course setting and participation with regard to the talent cultivation subsidy}

The courses conducted under the Taiwanese government's talent cultivation subsidy had to cover three areas, namely preparation for industry upgrade and service transformation, digital and precision marketing, and marketing promotion of the Taiwanese Tourism Bureau's tourism policy. These three areas emphasize that the Taiwanese lodging industry must adjust in response to the changes caused by the COVID-19 pandemic and integrate technology and marketing to help the industry improve its operation. The scale of the subsidy provided by the government was based on the number of employees participating in the training. The higher the number of employees completing the training, the higher was the subsidy from the government. Frontline workers (nonmanagement posts) account for a high proportion of the total workers in the lodging industry (Ministry of Labor 2019, 2020). Data from the current study revealed that numerous frontline employees participated in the talent cultivation project. The training courses aimed to comprehensively popularize industry upgrade and transformation as well as technology and marketing among all members of the Taiwanese lodging industry regardless of their rank to ensure that workers were aware of the considerable adjustment required under the changes caused by the COVID-19 pandemic. This understanding is crucial for not only managers but also nonmanagement employees.

In this study, the hotels participating in training were discovered to invite a higher proportion of managerial-level personnel, particularly middle-level managers, to the training than would be expected given the proportion of management personnel in the Taiwanese lodging industry. The aforementioned finding indicates that these hotels wanted managerial-level employees to participate in the comprehensive training. Basic-level managers are busy with on-site job management; middle-level managers mostly conduct on-site supervision and control; and high-level managers are involved in task-related decision-making (Ministry of Labor 2020). The key to the talent cultivation courses was industry upgrade and technology-based marketing that assists operation. This study revealed that middle-level managers could use their management 
knowledge during the training and were more satisfied with the training than were the other employees. Thus, the management knowledge provided in the training was most helpful to the middle-level managers.

\subsection{Research limitations}

With regard to the sampling in this study, because the institutions offering training courses were various (industry guilds, associations, and enterprises), the teachers, courses, training duration, and training resources of each course held in different cities and counties differed. Industry guilds and associations arranged training courses for hotels, and trainees from various hotels may have attended these courses. With regard to the courses offered by enterprises, the course content may have been customized according to the enterprises' needs (excluding the key required content), and the teachers were selected by the enterprises. The trainees in a training program were mostly from the enterprise that conducted the training, and training was conducted mostly in hotel meeting rooms. The data obtained in this study were mainly collected from participants in the training courses offered by Taiwanese tourist hotels. Consequently, customized training and overall conditions may have affected the trainees' questionnaire responses.

According to the data from the Executive Information System, Tourism Bureau, MOTC (2020a), the tourist hotels in Greater Taipei, Taichung, and Kaohsiung account for $41 \%, 6 \%$, and $9 \%$ of all hotels in Taiwan, respectively. By comparison, this study had more participants from Greater Taipei and Kaohsiung. According to the statistics of the MOTC, workers from the dining, room, management, and other departments account for $44 \%, 29 \%, 16 \%$, and $11 \%$ of all employees in Taiwanese tourist hotels, respectively. In the present study, the percentages of workers from the dining, room, and logistics departments were $46 \%, 35.4 \%$, and $18 \%$, respectively. The percentage of employees from the dining department was similar between the samples of the MOTC and current study. However, this study had a different participant profile compared with that in the official MOTC data, with the ratios of employees from the room and logistics departments being higher in the research sample than in the MOTC data.

Author contributions F-YL designed, conducted, and wrote this manuscript.

Funding No funds, grants, or other support was received.

Declarations

Conflict of interest The author has no financial or proprietary interests in any material discussed in this article. 


\section{References}

Alonso A, Kok S, Bressan A, O’Shea M, Sakellarios N, Koresis A, Solis M, Santoni L (2020) COVID19, aftermath, impacts, and hospitality firms: an international perspective. Int J Hosp Manag 91:102654. https://doi.org/10.1016/j.ijhm.2020.102654

Bhatia M, Stewart A, Wallace A, Kumar A, Malhotra A (2020) Evaluation of an in-situ neonatal resuscitation simulation program using the new world Kirkpatrick model. Clin Simul Nurs 50:27-37. https://doi.org/10.1016/j.ecns.2020.09.006

Central Bank of the Republic of China (Taiwan) (2020) NT\$/US\$ closing rate. https://www.cbc.gov.tw/ tw/lp-645-1.html. Accessed 10 Oct 2020

Chen L, Tseng C (2012) Benefits of cross-functional training: three departments of hotel line supervisors in Taiwan. J Hosp Tour Manag 19(1):115-122. https://doi.org/10.1017/jht.2012.13

Chen M, Wang Y (2006) Input-process-effectiveness: a model for evaluating training. Int J Hum Resour Manag 6(1):75-99. https://doi.org/10.6147/JHRM.2006.0601.04

Chen T, Jeang S, Liu Y (2012) A training evaluation study based on Kirkpatrick's four-level evaluation model in public sector training. Rev Agric Ext Sci 29:24-44. https://doi.org/10.29788/RAES. 201207.0002

Chi J, Lee H, Liu C, Hsu C (2007) The relationship of employees' learning attitude and learning satisfaction. Bio Leis Ind Res 5(1):58-76. https://doi.org/10.30133/BLIR.200706.0005

Chouhan V, Srivastava S (2014) Understanding competencies and competency modeling-a literature survey. IOSR J Bus Manag 16(1):14-22

Executive Information System, Tourism Bureau, MOTC (2020a) Monthly report on tourist hotel enterprise operations in Taiwan. https://admin.taiwan.net.tw/FileUploadCategoryListC003330.aspx? CategoryID=0dcf358f-f875-452d-8d14-2b715d02ab1a\&appname $=$ FileUploadCategoryListC00 3330. Accessed 06 Oct 2020

Executive Information System, Tourism Bureau, MOTC (2020b) Monthly report on hotel enterprise operations in Taiwan. https://admin.taiwan.net.tw/FileUploadCategoryListC003330.aspx?Categ oryID=fc9ec23b-281f-4a71-9861-14a1b0bbf4de\&appname=FileUploadCategoryListC003330. Accessed 10 Oct 2020

Executive Yuan (2020) All session bills. https://www.ey.gov.tw/Page/448DE008087A1971/46e8b1b83758-4732-8f15-d2254bf9ee4d. Accessed 02 Oct 2020

Falletta S (1998) Evaluating training programs: the four levels. Am J Eval 19(2):259-261

Farjad S (2012) The evaluation effectiveness of training courses in University by Kirkpatrick Model (Case study: Islamshahr University). Procedia Soc Behav Sci 46:2837-2841

Filimonau V, Derqui B, Matute J (2020) The COVID-19 pandemic and organizational commitment of senior hotel managers. Int J Hosp Manag 91:102659. https://doi.org/10.1016/j.ijhm.2020.102659

Hao F, Xiao Q, Chon K (2020) COVID-19 and China's hotel industry: impacts, a disaster management framework, and post-pandemic agenda. Int J Hosp Manag 90:102636. https://doi.org/10.1016/j.ijhm. 2020.102636

Hsieh A, Chang H (2010) The effects of trainer-trainee fit on training satisfaction. Chung Hua J Manag 11(1):23-40. https://doi.org/10.30053/CHJM.201003.0002

Kaushal V, Srivastava S (2021) Hospitality and tourism industry amid COVID-19 pandemic: perspectives on challenges and learnings from India. Int J Hosp Manag 92:102707. https://doi.org/10.1016/j. ijhm.2020.102707

Kirkpatrick J, Kirkpatrick W (2016) Kirkpatrick's four levels of training evaluation. American Society for Training \& Development, Alexandria

Laws \& Regulations Database of the Republic of China (2020). Act for the development of tourism. https://law.moj.gov.tw/ENG/LawClass/LawAll.aspx?pcode=K0110001. Accessed 11 Oct 2020

Ministry of Health and Welfare(2020) Taiwan timely identifies first imported case of 2019 novel coronavirus infection returning from Wuhan, China through onboard quarantine; Central Epidemic Command Center (CECC) raises travel notice level for Wuhan, China to Level 3: Warning. https://www. cdc.gov.tw/En/Bulletin/Detail/pVg_jRVvtHhp94C6GShRkQ?typeid=158. Accessed 05 Oct 2020

Ministry of Labor (2019) Survey on wage by occupation for 2019. https://statdb.mol.gov.tw/html/svy08/ 0835menu.htm. Accessed 17 Oct 2020

Ministry of Labor (2020) Lodging industry. https://www.mol.gov.tw/statistics/2475/2477/3541/. Accessed 17 Oct 2020

Moldovan L (2016) Training outcome evaluation model. Proc Technol 22:1184-1190 
Relief package for tourism and transportation amid COVID-19 pandemic (2020) Rules. https://event. motc.gov.tw/home.jsp?id=2189\&parentpath=0,2129,2185\&websiteid=202002100001. Assessed 18 Oct 2020

Sakthi T, Moshi A (2021) Effectiveness measurement study on entrepreneurship awareness camp for technical education students using Kirkpatrick's model. Mater Today Proc 45(2):1609-1613. https:// doi.org/10.1016/j.matpr.2020.08.419

Salem E, Abdien M (2017) Implementation of employee cross-training during perilous conditions in hotels. Tour Manag Perspect 23:68-74. https://doi.org/10.1016/j.tmp.2017.05.005

Shum C, Gatling A, Shoemaker S (2018) A model of hospitality leadership competency for frontline and director-level managers: which competencies matter more? Int J Hosp Manag 74:57-66. https://doi. org/10.1016/j.ijhm.2018.03.002

Sönmez S, Apostolopoulos Y, Lemke M, Hsieh Y (2020) Understanding the effects of COVID-19 on the health and safety of immigrant hospitality workers in the United States. Tour Manag Perspect 35:100717. https://doi.org/10.1016/j.tmp.2020.100717

The R.O.C Laws \& Regulations Database, Ministry of Justice (2016a) Regulations for administration of tourist hotel enterprises. https://law.moj.gov.tw/ENG/LawClass/LawAll.aspx?pcode=K0110006. Accessed 06 Oct 2020

The R.O.C Laws \& Regulations Database, Ministry of Justice (2016b) Regulations for the administration of hotel enterprises. https://law.moj.gov.tw/ENG/LawClass/LawAll.aspx?pcode=K0110014. Accessed 06 Oct 2020

Tourism Bureau, MOTC (2020a) Tourism Bureau worked on reviewing applications of COVID-19 bailout, 7 socialites and associations were approved to start the training program. https://admin.taiwan. net.tw/ActivitiesDetailC001200.aspx?Cond=ff17655b-ac65-4602-ade7-95cc5416cd56. Accessed 02 Oct 2020

Tourism Bureau, MOTC (2020b) Presentation of Tourism Bureau on bailout for the tourism sector v16 2020. https://admin.taiwan.net.tw/Uploads/1090528-\%E4\%BA\%A4\%E9\%80\%9A\%E9\%83\%A8\% E8\%A7\%80\%E5\%85\%89\%E7\%94\%A2\%E6\%A5\%AD\%E5\%8D\%94\%E5\%8A\%A9\%E6\%8E\%AA E6\%96\%BD\%E7\%B0\%A1\%E5\%A0\%B1v16.pdf. Accessed 02 Oct 2020

Tourism Bureau, MOTC (2020c) Over 85 thousand participants join the industrial transformation training program, and application deadlines for June 12, 2020. The tourism subsidy program is announced. https://admin.taiwan.net.tw/ActivitiesDetailC001200. aspx ?Cond=095a2dce-176a-4750-91b1455daeb09769. Accessed 02 Oct 2020

Tourism Bureau, MOTC (2020d) Rules for industrial transformation training program amid COVID-19 Pandemic. https://admin.taiwan.net.tw/FileUploadCategoryListC003220.aspx?CategoryID=824ae e03-1180-49e0-9ec0-cfa9e1903cae. Accessed 02 Oct 2020

Tourism Bureau, MOTC (2020e) Tourism, Chapter 2 domestic tourism, 2.2 evolution of tourism industry. http://admin.taiwan.net.tw/upload/contentFile/auser/b/wpage/chp1/1_2.2.htm. Accessed 11 Oct 2020

Tourism Bureau, MOTC (2020f) Annual statistical report on Tourism 2019 Taiwan, Republic of China. https://admin.taiwan.net.tw/Handlers/FileHandler.ashx?fid=b9822147-fd02-4dda-a283-281c0 d2321eb\&type $=4 \&$ no $=1$. Accessed 10 Oct 2020

Tourism Bureau, MOTC (2020g) Domestic travel subsidy program. https://admin.taiwan.net.tw/Activ itiesDetailC001100.aspx?Cond=6aabb42b-94ec-40ab-9748-52d9b2193e91. Accessed 17 Oct 2020

Wang C (2000) An empirical study for the model of factors affecting training performance: the perceptual and multi-variate. NTU Manag Rev 10(2):135-166. https://doi.org/10.6226/NTURM2000.10.2.135

World Tourism Organization (UNWTO) (2004) International tourism highlights, 2004th edn. WHO, Geneva

Wu M (2006) Structural equation modeling-the application of SIMPLIS. Wunan, Taipei, Taiwan.

Publisher's Note Springer Nature remains neutral with regard to jurisdictional claims in published maps and institutional affiliations. 